Canadian

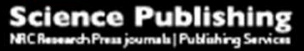

Canadian Journal of Civil Engineering Revue canadienne de génie civil

\title{
Prediction of seismic demand model for pulse like ground motions using artificial neural networks
}

\begin{tabular}{|r|l|}
\hline Journal: & Canadian Journal of Civil Engineering \\
\hline Manuscript ID & cjce-2017-0043.R3 \\
\hline Manuscript Type: & Article \\
\hline Date Submitted by the Author: & $26-J u l-2017$ \\
\hline $\begin{array}{r}\text { Complete List of Authors: } \\
\text { Is the invited manuscript for } \\
\text { consideration in a Special } \\
\text { Issue? : }\end{array}$ & Yazdannejad, kowsar; University of Kurdistan \\
\hline Keyword: & near-fault earthquakes, artificial neural network, Seismic demand model \\
\hline & \\
\hline
\end{tabular}


1 Article:

2 Prediction of seismic demand model for pulse like ground motions using 3 artificial neural networks

4 5

6 Kowsar Yazdannejad ${ }^{\mathrm{a}}$ and Azad $\operatorname{Yazdani}^{\mathbf{b}^{*}}$

$7 \quad{ }^{a}$ Ph.D. candidate, Department of Civil Engineering, University of Kurdistan, Sanandaj, Iran

$8 \quad{ }^{b}$ Associate Prof., Department of Civil Engineering, University of Kurdistan, Sanandaj, Iran 9

$10 *$ Corresponding author

11 Department of Civil Engineering, University of Kurdistan, P.O. Box 416, Sanandaj, Iran

12 Fax: (+) 98-87-33668457

13 E-mail: a.yazdani@uok.ac.ir

14

15

16

17

18

19

20

21

22

23

24

25 
27 Abstract: A probabilistic seismic demand model that relates ground motion intensity measures (IMs) to 28 the structural demand measures is a useful tool for reliability analysis of structures. It is common to utilize 29 the scalar seismic parameters or a vector of a few seismic parameters to reveal ground motion uncertainty. 30 However, for the qualification of an IM for representing the ground motion uncertainty, a larger vector of 31 greater seismic component is required. This study aims to use more parameters as vector IMs in the 32 demand model to achieve better estimation of the ground motion uncertainty. In this study, three-layer 33 feed forward neural network was used to predict the seismic demand model of the mid-rise RC buildings 34 for pulse like ground motions. The results indicate that due to the complexity of the relationship between 35 seismic response of structures and seismic intensity parameters, using artificial neural networks method is 36 more suitable than numerical methods to show uncertainties.

37 Keywords: Seismic demand model, near-fault earthquakes, artificial neural network 
52

53

54

\section{Introduction}

Assessment of the structural seismic damage under earthquake ground motions is an important issue in the seismic risk analysis in the context of seismic performance levels (Kostinakis and Athanatopoulou 2015). In engineering evaluation of structures with regards to performance levels, one of the most important parts of the errors is caused by ground motion uncertainty (Jalayer et al.2012). To include uncertainties rather than a full probabilistic explanation of the ground motion through the time, a probabilistic model consisting of a scalar parameter (like peak ground acceleration, Arias intensity, cumulative absolute velocity and spectral acceleration) or a few parameters as a vector, is used (Cornell and Luco 2007; Goulet et al. 2007; Jalayer et al. 2012). This creates many errors in specifying the uncertainty caused by ground motions (Jalayer et al.2012). The parameter or parameters known as Intensity Measure (IM) relate the ground excitation to structural seismic response in the probabilistic demand model. Thus far, various seismic parameters have been proposed as IM by researchers, but none of them have satisfied the sufficiency rule for the ground motion uncertainty (Cornell and Luco 2007; Goulet et al. 2007; Bradley et al. 2008; Jalayer and Cornell 2009; Elenas et al. 2011; Lin et al. 2011(I), 2011(II); Jalayer et al. 2012). Damage measure (DM) of structures after an earthquake is another important parameter that plays a significant role in predicting the demand model. Several parameters are considered to estimate structural damage including maximum inter-storey drift ratio or various damage indices (Krawinkler and Zohrei 1983; Park and Ang 1985; Dipasquale and Cakmak 1989; Colombo and Negro 2005; Kim et al. 2007; Padilla and Rodriguez 2009; Cao et al. 2014; Paal et al. 2015). Park-Ang damage index $\left(\mathrm{DI}_{\mathrm{PA}}\right)$ (Park and Ang 1985) is one of the most popular damage indices to measure component and global structural damage, especially for concrete structures. It is a linear combination of the maximum ductility and the hysteretic energy dissipation.

The seismic response of structures under the earthquake ground motions in near-fault areas can be significantly different from far-field areas (Liel and Champion 2012). These earthquakes have higher accelerations, velocities and restricted frequency content corresponding to the higher frequencies compared to those farther away. The amount of structural damage is more considerable in near-fault 
regions (Tothong and Cornell 2008; Liel and Champion 2012). Therefore, the behavior of the structures in these areas is more important for engineers.

There are several methods for solving an engineering problem, such as numerical methods, statistical methods, and methods based on intelligent calculations. Numerical methods are highly accurate methods. However, hybrid methods based on observations can also be more accurate in predicting engineering problems (Elenas et al. 2011; Baghirli 2015). In statistical methods, data collection is employed for analyzing a theoretical model and unknown model parameters are estimated. When the data is incomplete, statistical methods are not accurate. Moreover, these methods need an identified mathematical model (Baghirli 2015). It has been shown that artificial neural networks (ANNs) of modern computational methods are able to estimate various engineering problems, accurately (Reda Taha et al. 2003; Seleemah et al. 2005; Cobaner et al. 2008). The neural network can predict engineering problems well using past data and incomplete data or data associated with errors.

Neural networks can be very effective in solving various engineering problems that cannot be solved by statistical methods. They find relationships between input and output data, without any mathematical models and statistical approach. Hence, if there are several ways to solve a problem, the results of neural networks are with minimal errors (Rafiq et al. 2001; Seleemah et al. 2005; Lazarevska et al. 2014). There are several types of neural networks any of which can be employed depending on the nature and complexity of the problem. Backpropagation neural networks are one of the most important kinds of ANNs that are able to solve a wide range of issues (Jeng et al. 2003; Lagaros and Fragiadakis 2007).

This study proposes neural network techniques for developing a seismic demand model of RC structures, for near-fault pulse like ground motions. First, three different mid-rise RC moment resisting frames with 4, 6 and 8 story levels were chosen, and then nonlinear dynamic analysis was used to determine $\mathrm{DI}_{\mathrm{PA}}$ of frames under 30 near-fault pulse like ground motions with different intensity scales. A set of 13 major seismic parameters was selected as IM (Elenas et al. 2011; Jalayer et al. 2012; Kostinakis and Athanatopoulou 2015). A three-layer backpropagation neural network that consists of one input, one hidden and one output layer is employed for estimating the demand model. The number of neurons in the 
104 hidden layer for each training algorithm is modified so as to obtain the best performance. The log-sigmoid 105 transfer function was used for the neurons in the hidden layer while the output neuron uses the Purelin 106 transfer function. Four types of training algorithms, namely, Levenberg-Marquardt, Scaled Conjugate 107 Gradient, Broyden-Fletcher-Goldfarb-Shanno and Bayesian Regularization backpropagation algorithms 108 were investigated for their accuracy of predictions. The performance was estimated based on mean square 109 error (MSE).The early stopping method was employed for improving generalization and preventing the 110 over fitting of the networks. The adequacy of the demand model using neural networks was compared 111 with classical methods and the effect of increasing the number of IMs on improving the model was 112 evaluated. Finally, the steps for network training and estimating the seismic demand models for 113 maximum inter-storey drift (MSID), as a common and simple measure of structural damage, are 114 described.

\section{Seismic demand model}

117 In seismic risk analysis, an important area of research is the evaluation of expected seismic damage of the 118 structures under a specific earthquake ground motion (Ramamoorthy 2006). In order to estimate the 119 structural damage of an earthquake, it is necessary to introduce a demand model, which is composed of two important variables. One explains the ground motion intensity and the other explains the structural

121 performance. A good estimation of seismic performance and reduction in the variability of structural 122 response prediction depend on a successful correlation of these variables (Jalayer and Cornell 2009; 123 Jalayer et al. 2012).

124 The seismic performance of the structure is usually examined by DM. Amongst different response 125 quantities of structures, the overall damage indices (DIs) are highly regarded (Kim et al. 2007). The 126 global Park-Ang damage index model (DI $\mathrm{PA}_{\mathrm{PA}}$ (Park and Ang 1985), i.e. a linear combination of ductility 127 and energy absorption capacity parameters, was utilized as DM in this study. Consequently, the 128 identification of an IM, which sufficiently correlates with an appropriate engineering demand parameter, 129 is very important. Previous studies have used different scalar or vector IMs with two seismic parameters 
130

131

132

133

134

in order to estimate the damage potential of ground motions (Cornell and Luco 2007; Goulet et al. 2007; Bradley et al. 2008; Jalayer and Cornell 2009; Elenas et al. 2011; Jalayer et al. 2012).

In this study, a set of thirteen important seismic parameters that were introduced in previous studies as the effective parameters to represent ground motion intensity, was chosen as IM. In other words, the demand model is assumed as follows:

$$
\mathrm{DI}_{\mathrm{PA}}=f\left(\mathrm{PGA}, \mathrm{PGV}, \mathrm{ARMS}, \mathrm{VRMS}, \mathrm{SI}_{\mathrm{H}}, \mathrm{SED}, \mathrm{CAV}, \mathrm{VSI}, \mathrm{ARIAS}, \mathrm{S}_{\mathrm{a}}\left(\mathrm{T}_{1}\right), \mathrm{S}_{\mathrm{a}}{ }^{*}, \mathrm{EPA}, \mathrm{T}_{\mathrm{P}}\right)
$$

where $f$ is a function of the seismic parameters, and the other parameters are described in Table 1.

\section{Selected structural models and ground motion records}

To estimate the seismic demand model of RC structures for near-fault ground motions using ANN, three different mid-rise RC moment resistant structures (4, 6 and 8 storeys) were considered. Plan and elevations of the model frames and design details are shown in Figure 1. These frames were loaded and designed according to Iranian Codes (Iranian National Building Codes; Part 9, 2013; Standard No. 28005, 2014). In addition, the sectional dimensions and properties of loading are presented in Figure 1.Theselection of the critical frame depends on earthquake records. Longitudinal and transverse frames for different earthquake records were investigated and finally the frame A on the plan was selected and damage analysis was carried out by IDARC-2D (Kunnath et al. 2010). The value of 0.15 for $\beta$ in ParkAng damage model correlates closely with results based on other damage models (Cosenza et al. 1993). Thus, this value of $\beta$ is used in this study. This value shows moderate deterioration in IDARC software. The main periods of frames were 0.61, 0.71 and 0.75 s. The Kent and Park model (Kent and Park 1971) was utilized for concrete stress-strain curve. For each component cross-section, the moment-curvature relation is specified as a non-symmetric trilinear envelope with three degrading hysteretic parameters. Damage analysis was carried out to provide a measure of the accumulated damage sustained by the components of the structure, for each story level and the entire building.

The amount of information regarding the structural damage level induced by pulse like groundmotions can play a significant role in seismic design and evaluation of structures. Past research has shown 
that near-fault pulse like records tend to increase the displacement response of structures and its variation relative to non-pulse-like excitations (Liel and Champion 2012). In this study, a set of important nearfault pulse like earthquake records was chosen to estimate the demand model of near-fault structures. The ground motions were recorded through events with moment magnitude $\left(M_{w}\right)$ ranging from 5.6 to 7 and distance less than $30 \mathrm{~km}$. Table 2 shows the characteristics of the selected near-fault pulse like records. All records were selected from soft soil sites.

\section{Artificial neural network}

Artificial neural network is modeled from a biological nervous system of human beings. It has the ability to model any type of complex non-linear relationship (Jeng et al. 2003; Lagaros and Fragiadakis 2007). When the data is incomplete, neural networks are very effective. They are able to learn from experience and adapt to changing conditions (Beale et al. 2011).

\subsection{Network's Architecture}

Aneural network is composed of a large number of neurons, which are connected to each other at different layers. A network complexity varies according to the number of layers and the number of neurons in each layer (Lazarevska et al. 2014; Chojaczyk et al. 2015). A network consists of input layer, output layer, and a few hidden layers. The outputs are the final results of the network that are employed for analysis or solving problems. Each neuron has its own weight coefficient which shows the relative importance of the input (Jeng et al. 2003; Chojaczyk et al. 2015). Various types of neural networks exist according to their architecture (Baghirli 2015). Backpropagation networks have widespread applications in engineering problems (Lagaros and Fragiadakis 2007) and were utilized in this article. Figure (2-a) shows the architecture of a backpropagation neural network with two hidden layers. In backpropagation networks, the propagation takes place in a feed-forward manner, from the input layer to the output layer.

\subsection{Activation function}

The purpose of the transfer function is to check whether an output is generated with assigned weight and bias (Beale et al. 2011; Lazarevska et al. 2014). Multilayer networks utilize the log-sigmoid, tan-sigmoid 
181 and linear transfer functions as shown in Figure (2-b). When the sigmoid transfer function is used for the

182 last layer, the output is limited to a small range. Assuming a log-sigmoid transfer function for the hidden

183 layer and linear transfer function for the output layer, the model for seismic demand is as follows (Beale

184 et al. 2011):

$$
\mathrm{DI}_{\mathrm{PA}}=w_{2} *\left(\frac{1}{1+e^{-\left(\mathrm{w}_{1} \times \mathrm{IM}+\mathrm{b} 1\right)}}\right)+b_{2}
$$

185 where $w_{i}$ and $b_{i}$ are weight and bias matrix of layer $i$, respectively. The use of nonlinear activation

186 functions enhances the ability of the ANN to learn a nonlinear relationship (Lagaros and Fragiadakis 187 2007).

\subsection{Network's training process}

189 The proper training of a neural network plays an important role in their application for solving engineering problems. There are different types of backpropagation training algorithms, where each one has certain advantages and disadvantages depending on the complexity of the problem. In this study, Broyden-Fletcher-Goldfarb-Shanno (BFGS) (Dai 2013), Levenberg-Marquardt (LM) (Ardıçlığlu et al. 2007; Yu and Wilamowski 2011), Scaled Conjugate Gradient (SCG) (Möller 1993; Baghirli 2015) and Bayesian Regularization (BR) (Kayri 2016) algorithms were compared together. The configuration parameters of the algorithms are as shown in Table 3. These algorithms have represented better performance were compared to other algorithms in previous studies (Beale et al. 2011). Over fitting is an important problem that may occur during neural network training. The error on the training data becomes very small, but when new data is presented to the network, the error is large. An early stopping and regularization methods are two different techniques for improving generalization. In the early stopping technique, the available data is divided into three categories (Training, Validation and Testing). The training set is employed for computing the gradient and updating the network weights and biases. When the network begins to over fit the data, the error on the validation set begins to increase. When the validation error increases for a specified number of iterations, the training is stopped, and the weights and 
205

206

207

208

209

210

211

212

213

214

215

216

217

218

219

220

221

222

223

224

225

226

227

228

229

models (Beale et al. 2011; Demuth et al. 2014). A regularization method corrects the MSE performance function by adding a term comprising the mean of the sum of squares of the network weights and biases for preventing the over fitting. Using modified performance function leads to having smaller weights and biases for the network, and less likely to over fit (Beale et al. 2011; Demuth et al. 2014).

\section{Results and Discussion}

In this paper, backpropagation neural network with three layers (one input, one hidden and one output layer) was employed. The optimal number of neurons in the hidden layer for each training algorithm was determined based on the best network performance. The samples (total of 90 data from 30 analyses) were divided into three categories; training, validation and testing with ratios of $0.6,0.2$ and 0.2 , respectively and the early stopping method was used for improving generalization and preventing the over fitting of the networks. To increase the network efficiency, all data was normalized to the range of 0 to 1 . As shown in Figure (2-c), the log-sigmoid and Purelin transfer functions were utilized for neurons in the hidden and output layer, respectively. The performance of four algorithms in training the network were examined based on the error and better correlation of measured and predicted values of structural damage. To measure the accuracy of the network, MSE tool was employed. MATLAB software (2011) was used to design and train the network.

Proximity between calculated and estimated DI by different neural network algorithms is given in Figure 3. High correlation can be seen between the calculated and predicted DI by BR, LM and SCG algorithms. Furthermore, a great similarity can be seen between the training, validation and test data. For BR algorithm, correlation coefficients were almost one and the three sets of data matched, indicating the very good learning of the network. The variation of MSE in the network training with different algorithms through 5 epochs is shown in Figure 4. More details can be seen in Table 4. According to the results, it was observed that LM algorithm reached the highest rate in reduction of the amount of errors. In this algorithm, the network error reduced to zero after 5 epochs. Also, a similar trend is observed in the MSE 
error of testing and validation sets affirming that over fitting has not occurred. A comparison between different algorithms in reducing the errors of training data can be seen in Figure 5. High speed of LM algorithm in reducing errors can be clearly seen in this figure. After LM algorithm, BR and SCG algorithms had a good rate in reducing errors, noting that SCG had a large error margin compared to the other algorithms in the first step.

Figure 6 shows the variation of correlation coefficient by increasing the number of hidden layer neurons for three data sets and four experimental algorithms. As can be seen, the BR algorithm showed the best correlation and training. By increasing the number of the hidden layer neurons, this correlation has slightly improved. For this algorithm, the correlation coefficient is almost equal to 1.0. After BR algorithm, LM and SCG algorithms had a good performance and a slight increase in the hidden layer neurons will improve the network performance. However, the further increase will reduce the network performance. For BFGS algorithm, there is a major difference between the correlation coefficient of the training data with the other two categories; hence the learning of this algorithm is not satisfactory.

To investigate the role of seismic parameters' numbers as IM to reduce uncertainty, a comparison between the proposed IM and several IMs with different seismic parameters was performed using ANNs. The seismic parameters of IMs are described in Table 5. The correlation coefficient between the calculated values of $\mathrm{DI}_{\mathrm{PA}}$ and the predicted values and the MSE were compared in Figure 7. For network training, the LM method and 30 neurons in the hidden layer were used. As can be seen, by considering more seismic parameters as an IM, the correlation coefficient increased and MSE significantly reduced. the seismic ground motions should be taken into account. The residual plot that represents the remaining values of the structural response relative to the predicted values was used to assess the adequacy of 252 models. The residual plots for the four IMs with different numbers of seismic parameters and neural 253 network techniques were compared in Figure 8. According to Figure 8, for IM1, the points are well 254 distributed around the zero line without a particular trend. Thus, the assumption of homogeneity of 255 variances on the errors can be concluded. For this IM, the correlation coefficients between the residuals 
tend towards zero, which is very suitable. By reducing the vector space for IM, the average amount of 257 data away from the zero line and the correlation coefficient between the residuals increases which 258 indicates the inadequacy of the model. In addition, the range of the remaining changes significantly 259 increased by reducing the vector space of IM. The probability and density plot of residuals for these IMs 260 can be seen in Figure 9. For IM1, the standard deviation of residuals is less than three other IMs and the 261 probability of occurrence has a steeper slope. These results suggest that the use of scalar or small vector 262 IMs is not sufficient to show earthquake uncertainty and a more accurate demand model requires 263 consideration of more parameters of the earthquake. In addition, a comparison between the ANN method 264 and the classical method was made for two IMs (Sa* and $\left.\left[\mathrm{S}_{\mathrm{a}}\left(\mathrm{T}_{1}\right), \mathrm{S}_{\mathrm{a}}\left(\mathrm{T}_{2}\right)\right]\right)$. In the classical method, 265 according to previous studies, exponential relationship is assumed for the demand model (Cornell et al. 266 2002; Gardoni et al. 2002; Ramamoorthy 2006; Baker 2007; Jalayer et al. 2012). A logarithmic transformation of demand model is as follows:

$$
\begin{gathered}
\ln (D I)=a+b \ln \left(S a^{*}\right) \\
\ln (D I)=a+b \ln \left(S_{a}\left(T_{1}\right)\right)+c \ln \left(S_{a}\left(T_{2}\right)\right)
\end{gathered}
$$

The correlation coefficient between the calculated values and predicted values of the structural response and the error of models for these IMs are shown in Table 6. According to Table 6, it is observed that the use of neural networks compared with classical methods leads to greater solidarity and less error.

271 By investigating the residual plot for the two IMs shown in Figure 10, better efficiency of the demand 272 model using neural networks compared to the classical model can be seen.

273 In the following, seismic demand curves for some scalar IMs and vector IMs with two seismic 274 parameters using neural networks are shown in Figure 11. For IMs with three or more seismic parameters, 275 slicing is used for better representation. For example, a few slices of CAV, VSI and ARIAS for demand 276 curve with [CAV,VSI, ARIAS] as IM are shown in Figure 11. According to Figure 11, it is observed that 277 demand curves are monotonic and physically understandable which represents a good training of 278 networks. Given that maximum inter-storey drift (MISD) is simple and is a common measure for damage 279 assessment of structures, we consider MISD as DM in addition to the Park-Ang damage index. For MISD 
as well as $D I_{P A}$, the trained networks had a good performance to predict the seismic demand model. In

281 this case, in general, networks with more seismic parameters as IM had a better performance. For 282 example, the correlation coefficient between the predicted values of damage measure and the calculated 283 values for MISD and $D I_{P A}$ as DMs, are compared in Figure 12. A high correlation for PGV (IM13) and 284 MISD compared with $D I_{P A}$ is an interesting point. Figure 13 shows the seismic demand models for some 285 scalar and vector IMs and MISD as DM.

286 According to above comparisons, the use of modern techniques such as neural networks to estimate 287 the relationship between IM and DM, due to the complexity of the problem, is more efficient and better suited to demonstrate uncertainties. On the other hand, the superiority of ANNs over classical methods revealed that assuming a simple mathematical model relationship between IM and DM is not suitable for this purpose. Neural networks are less sensitive to errors in data and can work well with incomplete data. The ability to learn from examples is what makes neural networks more powerful and flexible. They can be connected to a large number of input and output data with minimum error.

\section{Conclusion}

In this study, a three-layer back propagation neural network was employed for predicting the demand model of mid-rise RC structures, and the accuracy of four different training algorithms (LM, BR, SCG and BFGS) was investigated. The input layer consisted of a set of 13 seismic parameters as IM that were determined for 30 near-fault pulse like ground motions with different intensity scales. The output vector with the same length was composed of the Park-Ang damage index and the maximum interstorey drift, corresponding to each input vector. High correlation between the calculated values and the predicted values by the trained neural network demonstrates the ability of neural networks (especially with BR and

302 LM algorithms) to estimate the structural demand model. For the BR and LM algorithms, correlation coefficients of the results for the training data set, were 0.997 and 0.95 respectively, indicating an excellent accuracy of these methods in training the network. Furthermore, the correlation coefficient for training, validation and testing data set were similar and close together indicating the high-quality of the 
network. SCG algorithm also performed well, but BFGS is not recommended for this issue. For different algorithms, increasing the number of neurons in the hidden layer to a certain extent will improve the network performance, but a further increase will reduce the network performance. In addition, based on the ability of the trained networks, using the networks with more hidden layers, due to the complexity, is not recommended. The adequacy analysis of different demand models indicates that the classical method, assuming a mathematical model with a linear relationship between the logarithms of the seismic response of structures and the intensity measure of earthquakes, is not very accurate and non-classical methods like neural networks can be very effective, especially for pulse like earthquakes. The comparison of different demand models with different number of seismic parameters as IM suggests that to achieve better evaluation of the structural performance after the earthquake, especially in near-fault areas, the seismic effect of various parameters should be considered together.

\section{Acknowledgments}

The authors would like to thank the anonymous reviewers for comments which helped to improve the manuscript.

\section{References}

Ardıçlığlu ,M., Kişi,Ö., and Haktanır ,T. 2007. Suspended sediment prediction using two different feed-forward back-propagation algorithms. Canadian Journal of Civil Engineering, 34(1): 120-125.

Baghirli, O. 2015. Comparison of Lavenberg-Marquardt, Scaled Conjugate Gradient and Bayesian Regularization back propagation algorithms for multistep ahead wind speed forecasting using multilayer perception feed forward neural network. Master thesis, Uppsala University, Department of Earth Sciences, Campus Gotland.

Baker,J.W. 2007. Probabilistic structural response assessment using vector-valued intensity measures. Earthquake Engineering and Structural Dynamics,36(13):1861-1883.

Beale, M.H., Hagan, M.T., and Demuth, H.B. 2011. Neural network toolbox for use with MATLAB. User's Guide. 
331 Bradley, B.A.,Cubrinovski, M.,Dhakal, R.P.,and MacRae, G.A. 2008. Intensity measures for the seismic performance of pile foundations. Soil Dynamic and Earthquake Engineering, 29(6): 1046-1058.

333 Cao, V.V.,Ronagh, H.R., Ashraf,M., and Baji, H. 2014. A new damage index for reinforced concrete structures. 334 Earthquake and Structures, 6(6): 581-609.

335

Chojaczyk, A.A.,Teixeira, A.P.,Neves, L.C.,Cardoso, J.B., and Guedes Soares, C. 2015. Review and application of Artificial Neural Networks models in reliability analysis of steel structures. Structural Safety,52(Part A): 78-89.

Cobaner, M., Seckin, G., and Kisi ,O. 2008. Initial assessment of bridge backwater using an artificial neural network approach. Canadian Journal of Civil Engineering, 35(5): 500-510.

Colombo, A., and Negro, P. 2005. A damage index of generalised applicability. Engineering Structures,27(8): 11641174.

Cosenza, E., Manfredi, G., and Ramasco, R. 1993. The use of damage functional in earthquake-resistant design: a comparison among different procedures. Structural Dynamics and Earthquake Engineering, 22: 855-868.

Cornell, C.A., Jalayer, F.,Hamburger, R.O., and Foutch, D.A. 2002. Probabilistic basis for the 2000 SAC Federal Emergency Management Agency steel moment frame guidelines. Journal of Structural Engineering,128(4): 526533.

Cornell, C.A., and Luco, N. 2007.Structure-specific scalar intensity measures for near-source and ordinary earthquake ground motions. Earthquake Spectra,23(2): 357-392.

Dai, Y.H. 2013. A perfect example for The BFGS method. Mathematical Programming, 138(1): 501-530.

Demuth, H.B., Beale, M.H., De Jess, O., and Hagan, M.T. 2014. Neural network design 2nd, Martin Hagan Publisher, USA, 800 pages.

Dipasquale, E., and Cakmak, A.S. 1989. On the relation between local and global damage indices. Technical Report NCEER-89-0034, State University of New York at Buffalo.

Elenas, A., Vrochidou,E., Alvanitopoulos, P.F., and Andreadis, I. 2011. Classification of seismic damages in buildings using fuzzy logic procedures. Computational Methods in Stochastic Dynamics, 26: 345-344.

Gardoni, P.,Der Kiureghian, A.,and Mosalam, K.M. 2002. Probabilistic capacity models and fragility estimates for RC columns based on experimental observations. Journal of Engineering Mechanics, 128(10):1024-1038. 
357 Goulet, C.A., Haselton, C.B.,Reiser, J.,Beck, J.L.,Deierlein, G.G., Porter, K.A., and Stewart, J.P. 2007. Evaluation of the seismic performance of a code-conforming reinforced-concrete frame building from seismic hazard to collapse safety and economic losses. Earthquake Engineering and Structural Dynamics,36(13): 1973-1997.

Iranian National Building Codes, Part 9- design and construction of R.C. buildings. 2013. Building and Housing Research Center, Iran (In Persian).

Jalayer, F.,Beck,J.L., and Zareian, F. 2012. Analyzing the sufficiency of alternative scalar and vector intensity measures of ground shaking based on information theory. Journal of Engineering Mechanics,138(3): $307-316$.

Jalayer, F., and Cornell, C.A. 2009. Alternative nonlinear demand estimation methods for probability-based seismic assessments. Earthquake Engineering and Structural Dynamics,38(8): 951-972.

Jeng, D.S., Cha, D.H.,and Blumenstein, M. 2003. Application of neural network in civil engineering problems. Proceedings of the International Conference on Advances in the Internet, Processing, Systems and Interdisciplinary Research.

Kayri, M. 2016. Predictive abilities of Bayesian Regularization and Levenberg-Marquardt algorithms in artificial neural networks: A comparative empirical study on social data. Mathematical and Computational Applications, 21(20): 1-11.

374 Kim, T-H., Kim, Y-J., Kang, H-T., and Shin, H-M. 2007. Performance assessment of reinforced concrete bridge 375 columns using a damage index. Canadian Journal of Civil Engineering, 34(7): 843-855.

376 Kostinakis, K.G., and Athanatopoulou, A.M. 2015. Prediction of seismic damage using scalar Intensity Measures

Kent, D.C., and Park, R. 1971. Flexural members with confined concrete. Journal of the Structural Division, ASCE 97(7): 1969-1990.

Kim, T-H., Kim, Y-J., Kang, H-T., and Shin, H-M. 2007. Performance assessment of reinforced concrete bridge

based on integration of spectral values. International Journal of Environmental, Chemical, Ecological. Geological and Geophysical Engineering,9(1): 1117-1129.

Krawinkler, H., and Zohrei, M. 1983. Cumulative damage in steel structures subjected to earthquake ground motion. Computers and Structures,16(1-4): 531-541.

381 Kunnath, S.K.,Reinhorn,A.M.,and Lobo, R.F. 2010. IDARC Version 7: A program for the inelastic damage 382 analysis of RC structures. Technical Report, National Center for Earthquake Engineering Research, State University of New York, Buffalo, NY. 
384

385

386

387

388

Lagaros, N.D., and Fragiadakis, M. 2007. Fragility assessment of steel frames using neural networks. Earthquake Spectra, 23(4):735-752.

Lazarevska, M.,Knezevic, M.,Cvetkovska, M., and Trombeva-Gavriloska, A. 2014. Application of artificial neural networks in civil engineering. Tehnicki Vjesnik,21(6): 1353-1359.

Liel, A.,and Champion,C. 2012. The effect of near-fault directivity on building seismic collapse risk. Earthquake Engineering and Structural Dynamics,41(10): 1391-1409.

Lin, L., Naumoski , N., Saatcioglu, M., and Foo, S. 2011. Improved intensity measures for probabilistic seismic demand analysis. Part 1: development of improved intensity measures. Canadian Journal of Civil Engineering, 38(1): 79-88, 10.1139/L10-110.

Lin, L., Naumoski , N., Saatcioglu, M., and Foo, S. 2011. Improved intensity measures for probabilistic seismic demand analysis. Part 2: application of the improved intensity measures Canadian Journal of Civil Engineering, 38(1): 89-99, 10.1139/L10-111.

MATLAB (2011) Matlab user manual. Mathwork Inc. Lowell, MA, USA.

Möller, M.F. 1993. A scaled conjugate gradient algorithm for fast supervised learning. Neural Networks,6(4): 525533.

Paal, S., Jeon, J., Brilakis, I., and DesRoches, R. 2015. Automated damage index estimation of reinforced concrete columns for post-earthquake evaluations. Journal of Structural Engineering,141(9): 1-13.

Padilla, D., and Rodriguez, M. 2009. A damage index for the seismic analysis of reinforced concrete members. Journal of Earthquake Engineering,13(3): 364-383.

Park, Y.J., and Ang, A.H. 1985. Mechanistic seismic damage model for reinforced concrete. Journal of Structural Engineering, ASCE 111(4): 722-739.

Rafiq, M.Y., Bugmann, G.,and Easterbrook, D.J. 2001. Neural network design for engineering applications. International Journal of Computers and Structures,79(17): 1541-1552.

Ramamoorthy, S.K. 2006. Seismic fragility estimates for reinforced concrete framed buildings. Ph.D Thesis, Texas A\&M University.

Reda Taha, M.M., Noureldin, A., El-Sheimy, N., and Shrive, N. G.2003. Artificial neural networks for predicting creep with an example application to structural masonry. Canadian Journal of Civil Engineering, 30(3): 523-532. 
411 Sankar Jegadesh, J.S., and Jayalekshmi, S.A. 2015. Review on artificial neural network concepts in structural 412 engineering applications. International Journal on Applications in Civil and Environmental Engineering,1(4): 6$413 \quad 11$.

414 Seleemah, A.A. 2005. A neural network model for predicting maximum shear capacity of concrete beams without 415 transverse reinforcement. Canadian Journal of Civil Engineering, 32(4): 644-657.

416 Standard No. 2800-5, Iranian Code of Practice for Seismic Resistant Design of Buildings, 4rd Revision. 2014.

417 Building and Housing Research Center, Iran (In Persian).

418 Tothong, P., and Cornell, C.A. 2008. Structural performance assessment under near-source pulse-like ground 419 motions using advanced ground motion intensity measures. Earthquake Engineering and Structural 420 Dynamic,37(7): 1013-1037.

421 Yu, H., and Wilamowski, B.M. 2011. Levenberg Marquardt training industrial electronics handbook. vol. 5 422 Intelligent Systems, 2nd Edition, chapter 12, 12-1 to 12-15. 
Table 1. The intensity measures (IMs) considered

\begin{tabular}{|c|c|c|c|}
\hline No. & $\begin{array}{l}\text { Seismic Intensity } \\
\text { Parameters (IMs) }\end{array}$ & Description the IM & Definition \\
\hline $\mathrm{X}_{1}$ & PGA & Peak Ground Acceleration & - \\
\hline $\mathrm{X}_{2}$ & PGV & Peak Ground Velocity & - \\
\hline $\mathrm{X}_{3}$ & ARMS & Root Mean Square Acceleration & $\sqrt{\frac{1}{t_{e}}} \int_{0}^{t_{e}}(\ddot{x})^{2} d t$ \\
\hline $\mathrm{X}_{4}$ & VRMS & Root Mean Square Velocity & $\sqrt{\frac{1}{t_{e}} \int_{0}^{t_{e}}(\dot{x})^{2} d t}$ \\
\hline $\mathrm{X}_{5}$ & $\mathrm{SI}_{\mathrm{H}}$ & Spectrum Intensity after Housner & $\operatorname{PSV}(T, \xi) d T$ \\
\hline $\mathrm{X}_{6}$ & SED & Specific Energy Density & - \\
\hline $\mathrm{X}_{7}$ & CAV & Cumulative Absolute Velocity & $\int_{0}|\ddot{x}| d t$ \\
\hline $\mathrm{X}_{8}$ & VSI & Velocity spectrum intensity & $\int_{0.1} S_{v}(T, \xi) d T$ \\
\hline $\mathrm{X}_{9}$ & $\operatorname{ARIAS}\left(\mathrm{I}_{\mathrm{a}}\right)$ & Arias intensity & $\frac{\pi}{2 g} \int_{0}^{t_{e}} \ddot{x}^{2} d t$ \\
\hline $\mathrm{X}_{10}$ & $\mathrm{~S}_{\mathrm{a}}\left(\mathrm{T}_{1}\right)$ & Spectral acceleration at the fundamental period & - \\
\hline $\mathrm{X}_{11}$ & & Geometric mean of the spectral acceleration values at $T_{1}$ and $T_{2}$ & $\left(S_{a}\left(T_{1}\right) \cdot S_{a}\left(T_{2}\right)\right)^{0.5}$ \\
\hline $\mathrm{X}_{12}$ & EPA & Effective Peak Acceleration & $\frac{S A}{2 S}$ \\
\hline $\mathrm{X}_{13}$ & $\mathrm{~T}_{\mathrm{P}}$ & Predominant Period & \\
\hline
\end{tabular}


Table 2. Characteristics of the selected pulse like records

\begin{tabular}{|c|c|c|c|c|c|c|c|c|c|}
\hline No & Event & $\begin{array}{l}\text { Event date } \\
\text { Y-M-D }\end{array}$ & Station & $\begin{array}{l}\text { Magnitude } \\
\qquad\left(M_{w}\right)\end{array}$ & $\begin{array}{l}\text { Closest } \\
\text { Dist. } \\
(\mathrm{km})\end{array}$ & $\begin{array}{c}\text { Depth } \\
(\mathbf{k m})\end{array}$ & $\begin{array}{c}\text { PGA } \\
\text { (g) }\end{array}$ & $\begin{array}{l}T_{P} \\
(s)\end{array}$ & $\begin{array}{l}\text { Soil } \\
\text { Class }\end{array}$ \\
\hline 1 & San Fernando & 1971-02-09 & $\begin{array}{l}\text { Pacoima Dam (upper } \\
\text { left abut) }\end{array}$ & 6.6 & 1.8 & 8.4 & 1.055 & 1.64 & $\mathrm{C}$ \\
\hline 2 & Coyote Lake & 1979-08-06 & Gilroy \#6 & 5.7 & 3.1 & 10 & 0.315 & 1.23 & $\mathrm{C}$ \\
\hline 3 & Coyote Lake & 1979-08-06 & $\begin{array}{l}\text { Coyote Lake Dam } \\
\text { (southwest abut) }\end{array}$ & 5.7 & 6.13 & 10 & 0.245 & 2.11 & $\mathrm{C}$ \\
\hline 4 & Coyote Lake & 1979-08-06 & $\begin{array}{c}\text { San Juan Bautista - } \\
\text { Hwy 101/156 } \\
\text { Overpass }\end{array}$ & 5.7 & 20.67 & 10 & 0.2 & 2.84 & $\mathrm{C} / \mathrm{D}$ \\
\hline 5 & Morgan Hill & 1984-04-24 & $\begin{array}{l}\text { Coyote Lake Dam } \\
\text { (SW abut) }\end{array}$ & 6.2 & 0.5 & 9 & 1.138 & 1.07 & $\mathrm{C}$ \\
\hline 6 & Sierra Madre & $1991-06-28$ & $\begin{array}{l}\text { San Marino - } \\
\text { Southwestern } \\
\text { Academy }\end{array}$ & 5.6 & 18.74 & 12 & 0.19 & 1.58 & $\mathrm{C}$ \\
\hline 7 & Sierra Madre & $1991-06-28$ & LA-City Terrace & 5.6 & 25.69 & 12 & 0.12 & 1.3 & $\mathrm{C} / \mathrm{D}$ \\
\hline 8 & Palm Springs & 1986-08-07 & North Palm Spring & 6.1 & 4 & 12 & 0.23 & 1.4 & $\mathrm{D}$ \\
\hline 9 & Loma Prieta & 1989-10-18 & Gilroy Array\#2 & 6.9 & 11.1 & 18 & 0.370 & 1.73 & $\mathrm{D}$ \\
\hline 10 & Loma Prieta & $1989-10-18$ & Saratoga-Aloha Ave & 6.9 & 8.5 & 18 & 0.530 & 4.57 & $\mathrm{C}$ \\
\hline 11 & $\begin{array}{c}\text { Cape } \\
\text { Mendonico }\end{array}$ & $1992-04-25$ & Petrolia & 7 & 8.2 & 15 & 0.685 & 3.00 & $\mathrm{C}$ \\
\hline 12 & $\begin{array}{c}\text { Cape } \\
\text { Mendonico }\end{array}$ & $1992-04-25$ & $\begin{array}{c}\text { Fortuna-Fortuna } \\
\text { Boulevard }\end{array}$ & 7 & 19.95 & 15 & 0.120 & 3.9 & $\mathrm{C}$ \\
\hline 13 & Northridge & 1994-01-17 & $\begin{array}{l}\text { Pacoima Dam (upper } \\
\text { left abut) }\end{array}$ & 6.7 & 7 & 19 & 1.260 & 0.84 & $\mathrm{C}$ \\
\hline 14 & Northridge & 1994-01-17 & $\begin{array}{l}\text { LA-Century City CC } \\
\text { North }\end{array}$ & 6.7 & 23.4 & 19 & 0.262 & 1.12 & $\mathrm{D}$ \\
\hline 15 & Imperial Valley & $1979-10-15$ & $\begin{array}{l}\text { EC Meloland } \\
\text { Overpass FF }\end{array}$ & 6.5 & 0.1 & 12 & 0.318 & 3.3 & $\mathrm{D}$ \\
\hline 16 & Imperial Valley & $1979-10-15$ & $\begin{array}{c}\text { EC Country Center } \\
\text { FF }\end{array}$ & 6.5 & 7.3 & 12 & 0.237 & 4.42 & $\mathrm{D}$ \\
\hline 17 & Imperial Valley & $1979-10-15$ & Holtville Post Office & 6.5 & 7.7 & 12 & 0.258 & 4.8 & $\mathrm{D}$ \\
\hline 18 & Imperial Valley & $1979-10-15$ & $\begin{array}{c}\text { El Centro Differential } \\
\text { Array }\end{array}$ & 6.5 & 5.1 & 12 & 0.486 & 6.27 & $\mathrm{D}$ \\
\hline 19 & Imperial Valley & $1979-10-15$ & El Centro Array\#06 & 6.5 & 1.4 & 12 & 0.453 & 3.77 & $\mathrm{D}$ \\
\hline 20 & Imperial Valley & $1979-10-15$ & El Centro Array \#07 & 6.5 & 0.6 & 12 & 0.468 & 4.38 & $\mathrm{D}$ \\
\hline 21 & Imperial Valley & $1979-10-15$ & El Centro Array \#08 & 6.5 & 3.9 & 12 & 0.619 & 5.4 & $\mathrm{D}$ \\
\hline 22 & Imperial Valley & $1979-10-15$ & El Centro Array \#04 & 6.5 & 7 & 12 & 0.488 & 4.79 & $\mathrm{D}$ \\
\hline 23 & Imperial Valley & $1979-10-15$ & El Centro Array\#10 & 6.5 & 8.6 & 12 & 0.231 & 4.52 & $\mathrm{D}$ \\
\hline 24 & Imperial Valley & $1979-10-15$ & El Centro Array \#03 & 6.5 & 12.9 & 12 & 0.268 & 4.50 & $\mathrm{D}$ \\
\hline 25 & Imperial Valley & $1979-10-15$ & El Centro Array\#11 & 6.5 & 12.5 & 12 & 0.380 & 7.4 & $\mathrm{D}$ \\
\hline 26 & Kobe & 1995-01-16 & Takatori & 6.9 & 1.5 & 1.5 & 0.693 & 1.55 & $\mathrm{D}$ \\
\hline 27 & $\begin{array}{l}\text { Whittier } \\
\text { Narrows }\end{array}$ & 1987-10-01 & $\begin{array}{c}\text { Downey-Co Maint } \\
\text { Bldg }\end{array}$ & 6 & 20.8 & 9.5 & 0.2 & 0.88 & $\mathrm{D}$ \\
\hline 28 & $\begin{array}{l}\text { Whittier } \\
\text { Narrows }\end{array}$ & 1987-10-01 & $\begin{array}{c}\text { Norwalk-Imp } \\
\text { Highway }\end{array}$ & 6 & 20.4 & 9.5 & 0.213 & 0.90 & $\mathrm{D}$ \\
\hline 29 & $\begin{array}{l}\text { Whittier } \\
\text { Narrows }\end{array}$ & 1987-10-01 & $\begin{array}{c}\text { Lakewood-Del Amo } \\
\text { Boulevard }\end{array}$ & 6 & 26.68 & 9.5 & 0.245 & 0.93 & $\mathrm{D}$ \\
\hline 30 & $\begin{array}{l}\text { Whittier } \\
\text { Narrows }\end{array}$ & 1987-10-01 & Bell-Gardens & 6 & 17.8 & 9.5 & 0.3 & 0.82 & D \\
\hline
\end{tabular}


Table 3. Parameters of training algorithms

\begin{tabular}{lllll}
\hline Configuration Parameters & BFGS & LM & SCG & BR \\
\hline Maximum learning time (epochs) & 1000 & 1000 & 1000 & 1000 \\
Performance goal & 0 & 0 & 0 & 0 \\
Maximum validation failures & 6 & 6 & 6 & 6 \\
Initial mu & - & 0.001 & - & 0.005 \\
Mu decrease factor & - & 0.1 & - & 0.1 \\
Mu increase factor & - & 10 & - & 10 \\
Minimum performance gradient & $1 \mathrm{e}-6$ & $1 \mathrm{e}-10$ & $1 \mathrm{e}-6$ & $1 \mathrm{e}-10$ \\
Scale factor that determines sufficient reduction $(\boldsymbol{\alpha})$ & 0.001 & - & - & - \\
Scale factor that determines sufficiently large step size $(\boldsymbol{\beta})$ & 0.1 & - & - & - \\
Initial step size in interval location step $(\boldsymbol{\delta})$ & 0.01 & - & - & - \\
Parameter to avoid small reductions in performance $(\boldsymbol{\gamma})$ & 0.1 & - & - & - \\
Determine change in weight for second derivative approximation $(\boldsymbol{\sigma})$ & - & - & $5 \mathrm{e}-5$ & - \\
Parameter for regulating the indefiniteness of the Hessian $(\boldsymbol{\lambda})$ & - & - & $5 \mathrm{e}-7$ & - \\
\hline
\end{tabular}


477

478

Table 4. MSE error of ANN for different training algorithms from step 1 to step 5

\begin{tabular}{|c|c|c|c|c|c|c|c|c|c|c|c|c|}
\hline \multirow{2}{*}{ epoch } & \multicolumn{3}{|c|}{ LM } & \multicolumn{3}{|c|}{ BR } & \multicolumn{3}{|c|}{ SCG } & \multicolumn{3}{|c|}{ BFG } \\
\hline & Train & Validation & test & Train & Validation & test & Train & Validation & test & Train & Validation & test \\
\hline 1 & 0.280 & 0.271 & 0.279 & 0.302 & 0.298 & 0.283 & 0.314 & 0.345 & 0.310 & 0.755 & 0.718 & 0.729 \\
\hline 2 & 0.033 & 0.045 & 0.033 & 0.242 & 0.238 & 0.232 & 0.204 & 0.182 & 0.201 & 0.446 & 0.408 & 0.397 \\
\hline 3 & 0.012 & 0.014 & 0.012 & 0.192 & 0.189 & 0.187 & 0.189 & 0.162 & 0.179 & 0.410 & 0.362 & 0.384 \\
\hline 4 & 0.010 & 0.012 & 0.010 & 0.168 & 0.164 & 0.164 & 0.125 & 0.111 & 0.121 & 0.248 & 0.243 & 0.233 \\
\hline 5 & 0.009 & 0.010 & 0.009 & 0.045 & 0.043 & 0.045 & 0.090 & 0.087 & 0.095 & 0.099 & 0.087 & 0.074 \\
\hline
\end{tabular}

479

480

481

482

483

484

485

486

487

488

489

490

491

492

493

494

495

496 
499

Table 5.Different IMs with varies number of seismic parameters

\begin{tabular}{|c|c|}
\hline No. & Seismic parameters of IMs \\
\hline IM1 & [PGA, PGV, ARMS, VRMS, $\left.\mathrm{SI}_{\mathrm{H}}, \mathrm{SED}, \mathrm{CAV}, \mathrm{VSI}, \operatorname{ARIAS}\left(\mathrm{I}_{\mathrm{a}}\right), \mathrm{S}_{\mathrm{a}}\left(\mathrm{T}_{1}\right), \mathrm{S}_{\mathrm{a}}{ }^{*}, \mathrm{EPA}, \mathrm{T}_{\mathrm{P}}\right]$ \\
\hline IM2 & {$\left[\mathrm{PGV}, \mathrm{ARMS}, \mathrm{VRMS}, \mathrm{SI}_{\mathrm{H}}, \mathrm{SED}, \mathrm{CAV}, \mathrm{VSI}, \operatorname{ARIAS}\left(\mathrm{I}_{\mathrm{a}}\right), \mathrm{S}_{\mathrm{a}}\left(\mathrm{T}_{1}\right), \mathrm{S}_{\mathrm{a}}{ }^{*}, \mathrm{EPA}\right]$} \\
\hline IM3 & {$\left[\right.$ PGA, PGV, CAV, VSI, ARIAS $\left.\left(I_{a}\right), S_{a}\left(T_{1}\right), E P A\right]$} \\
\hline IM4 & {$\left[\mathrm{PGV}, \mathrm{CAV}, \mathrm{VSI}, \mathrm{ARIAS}, \mathrm{S}_{\mathrm{a}}\left(\mathrm{T}_{1}\right)\right]$} \\
\hline IM5 & {$[\mathrm{CAV}, \mathrm{VSI}, \mathrm{ARIAS}]$} \\
\hline IM6 & {$\left[\mathrm{CAV}, \mathrm{ARIAS}, \mathrm{S}_{\mathrm{a}}^{*}\right]$} \\
\hline IM7 & {$\left[\mathrm{S}_{\mathrm{a}}\left(\mathrm{T}_{1}\right), \mathrm{S}_{\mathrm{a}}^{*}\right]$} \\
\hline IM8 & {$\left[\mathrm{CAV}, \mathrm{S}_{\mathrm{a}}\left(\mathrm{T}_{1}\right)\right]$} \\
\hline IM9 & {$\left[\mathrm{S}_{\mathrm{a}}\left(\mathrm{T}_{1}\right), \mathrm{S}_{\mathrm{a}}\left(\mathrm{T}_{2}\right)\right]$} \\
\hline IM10 & $\mathrm{S}_{\mathrm{a}}\left(\mathrm{T}_{1}\right)$ \\
\hline IM1 1 & ARIAS \\
\hline IM12 & $\mathrm{S}_{\mathrm{a}}^{*}$ \\
\hline IM13 & PGV \\
\hline IM14 & PGA \\
\hline
\end{tabular}

501

502

503

504

505

506

507

508

509

510

511

512

513

514

515

516 
Table 6. Summary of regression analysis for two important IMs with two different methods

\begin{tabular}{ccccc}
\hline \multirow{2}{*}{$\mathbf{M}$} & \multicolumn{2}{c}{$\mathbf{R}^{\mathbf{2}}$} & \multicolumn{2}{c}{ MSE } \\
\cline { 2 - 5 } & Classical & ANN & Classical & ANN \\
\hline $\mathrm{S}_{\mathrm{a}}{ }^{*}$ & 0.442 & 0.523 & 0.302 & 0.272 \\
\hline$\left[\mathrm{S}_{\mathrm{a}}\left(\mathrm{T}_{1}\right), \mathrm{S}_{\mathrm{a}}\left(\mathrm{T}_{2}\right)\right]$ & 0.608 & 0.726 & 0.236 & 0.206 \\
\hline
\end{tabular}

521

522

523

524

525

526

527

528

529

530

531

532

533

534

535

536

537

538

539

540 


\section{$542 \quad$ Figure Captions}

543 Figure 1. Plan and elevation of the concrete frames

544 Figure 2. (a) Architecture of a back-propagation neural network; (b) Transfer Functions for back-

545 propagation networks; (c) Network used as a general function approximator

$546 \quad$ Figure 3. Comparison between calculated and estimated DI by different ANN algorithms

547 Figure 4. Changes in the error function MSE, for 3 sets of data with different algorithms

548 Figure 5. Comparison between different algorithms in reducing the errors

549 Figure 6. Variation of correlation coefficient, by increasing the hidden layer neurons

550 Figure 7. Comparison of results for different IMs using ANN method

$551 \quad$ Figure 8. Comparison of Adequacy of demand models with the residual plot

552 Figure 9. The probability of occurrence and density for the remaining of structural response using ANN

553 method

554 Figure 10. Check the adequacy of demand models with two important IMs with different methods

555 Figure 11. Seismic demand curves for some scalar and vector IMs and $\mathrm{DI}_{\mathrm{PA}}$ as $\mathrm{DM}$

556 Figure 12. Correlation coefficient between the predicted values of damage measure and the calculated

557 values for MISD and $\mathrm{DI}_{\mathrm{PA}}$

558 Figure 13. Seismic demand curves for some scalar and vector IMs and MISD as DM 


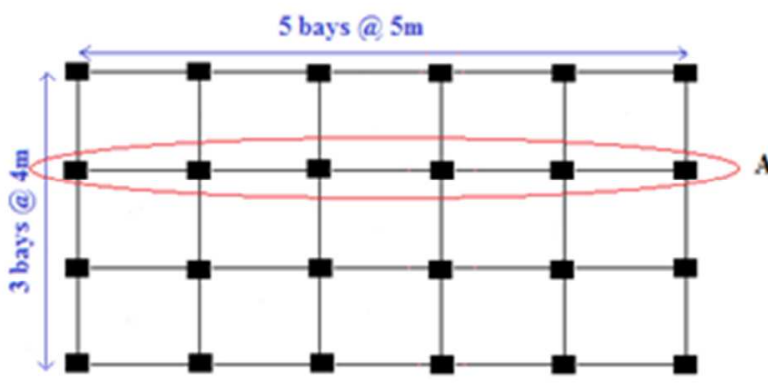

Restraints:

Columns fixed at base.

Connections:

Moment resisting connections were used.

\section{Loading:}

Dead load for all storeys: $500 \mathrm{~kg} / \mathrm{m}^{2}$.

Dead load of perimeter walls: $700 \mathrm{~kg} / \mathrm{m}$;

Live load for storeys: $200 \mathrm{~kg} / \mathrm{m}^{2}$;

Live load for roof: $150 \mathrm{~kg} / \mathrm{m}^{2}$;

Mass participation ratio of live load: $20 \%$

\section{Material properties:}

Characteristic strength of concrete: $250 \mathrm{Mpa}$;

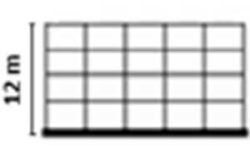

S4B5

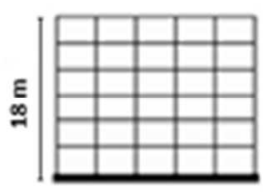

S6B5

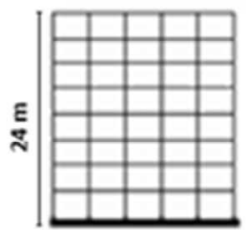

S8B5

$1^{n t}-2^{\text {sos }}$ floor: $50 \times 50 \mathrm{~cm}^{2}$,

$3^{\text {th }}-4^{\text {th }}$ floor: $45 \times 45 \mathrm{~cm}^{2}$

$1^{\text {nt }}-2^{\text {no }}$ floor: $60 \times 60 \mathrm{~cm}^{2}$

$3^{\mathrm{m}}-4^{\mathrm{m}}$ floor: $55 \times 55 \mathrm{~cm}^{2}$;

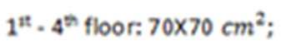

$5^{\text {th }} \cdot 8^{\text {th }}$ floor: $60 \times 60 \mathrm{~cm}^{2}$

$5^{\mathrm{m}} \cdot 6^{\mathrm{n}}$ floor: $50 \times 50 \mathrm{~cm}^{2}$

Figure 1. 


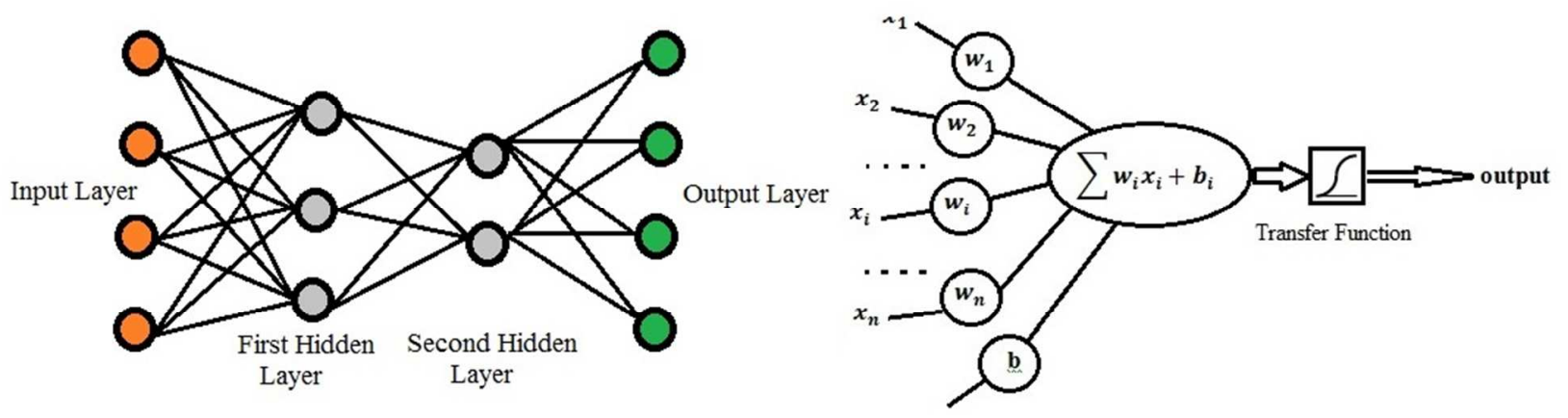

(a)
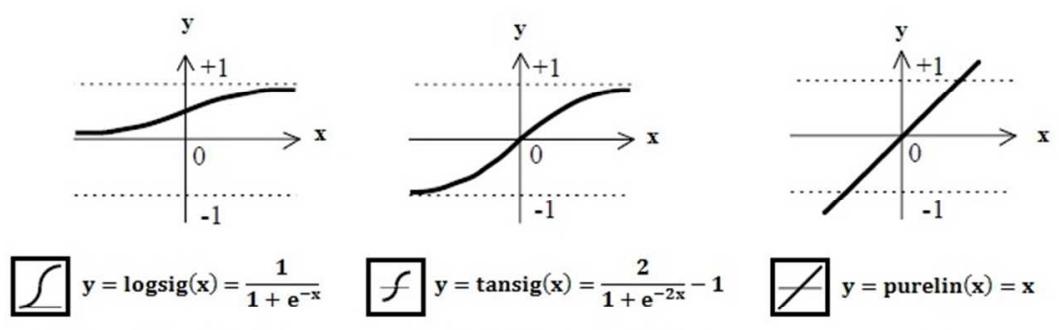
$f y=\operatorname{tansig}(x)=\frac{2}{1+e^{-2 x}}-1$
Tan-Sigmoid Transfer Function

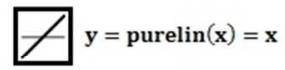

Log-Sigmoid Transfer Function

Linear Transfer Function

(b)

Input layer

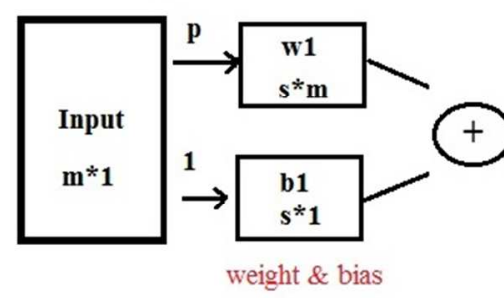

Hidden layer

Output layer

(c) 

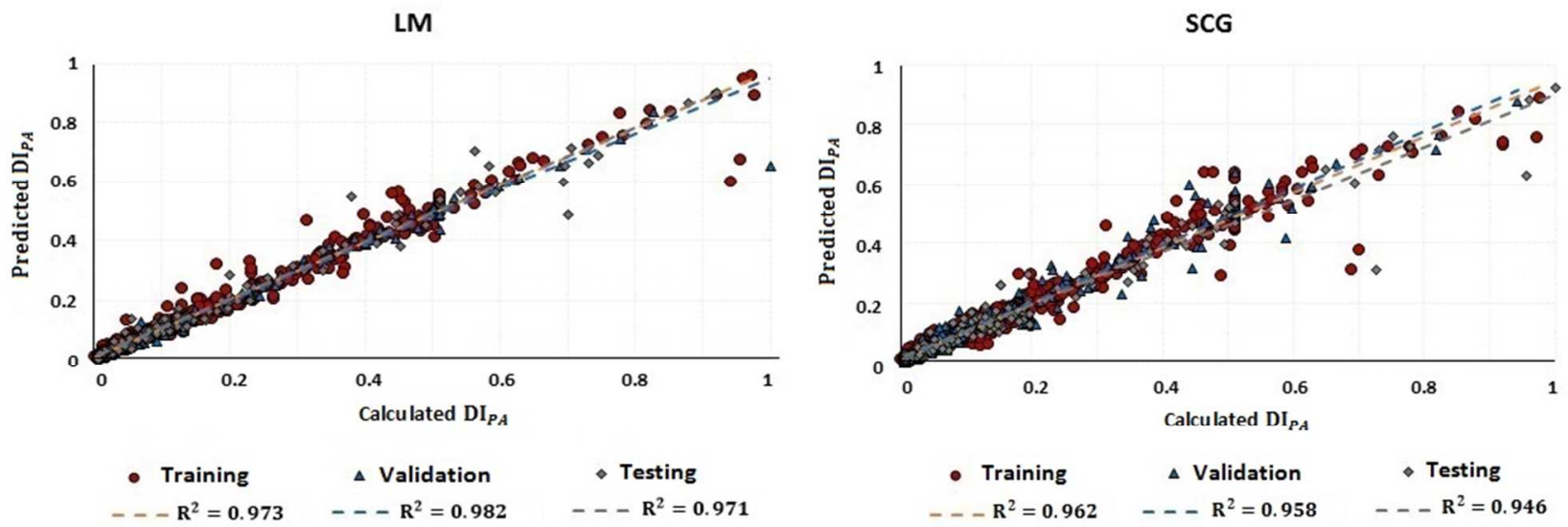

(a)

(c)

BR
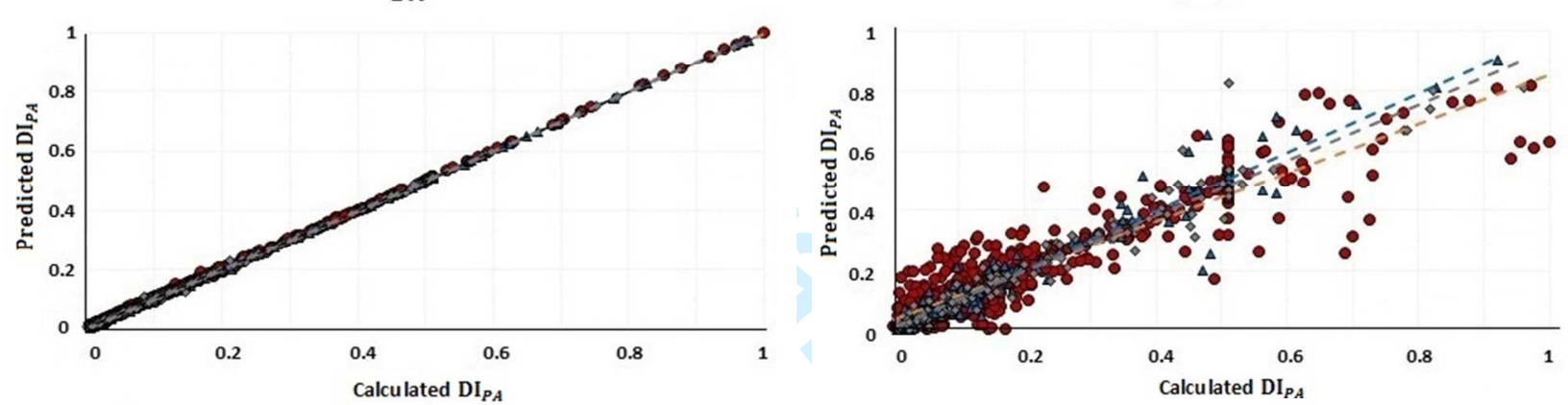

- Training

$\triangle$ Validation

- Testing

$---R^{2}=0.9997$

$---R^{2}=0.9997$

$---R^{2}=0.9996$

- Training

$\triangle$ Validation

- Testing

$---R^{2}=0.829$

$---R^{2}=0.943$

$--R^{2}=0.940$

(b)

(d)

Figure 3. 
601

602

603

604

605
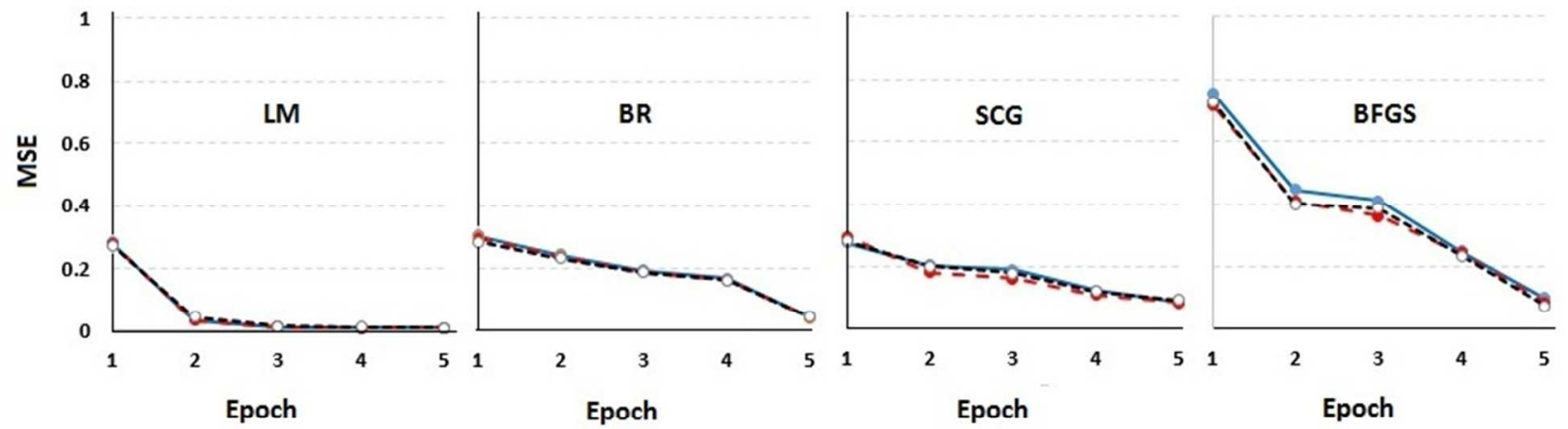

606

607

Figure 4.

608

609

610

611

612

613

614

615

616

617

618

619

620

621 

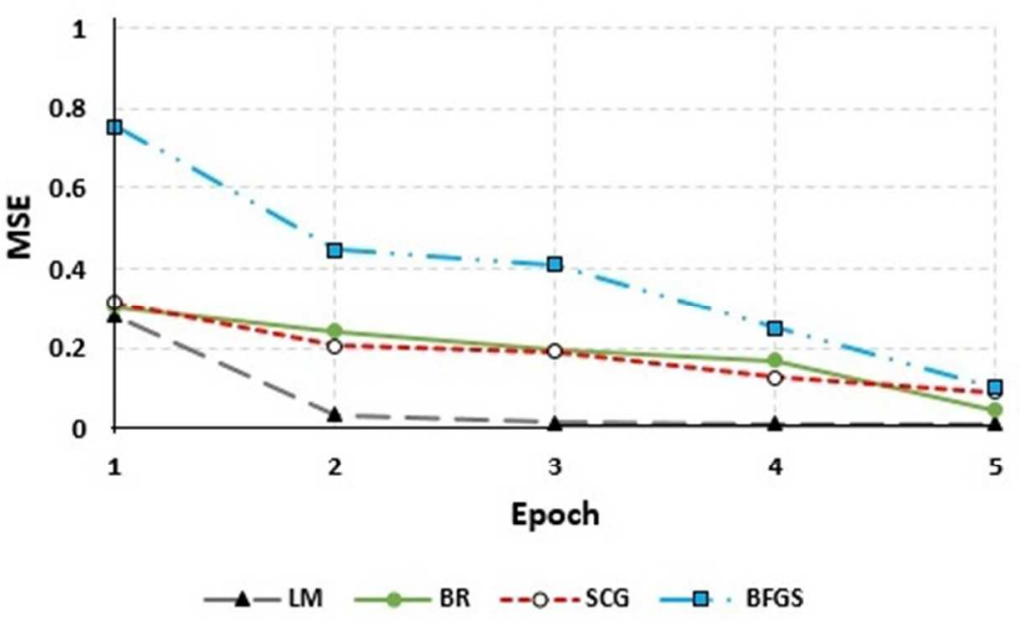

626

627

628

629

630

631

632

633

634

635

636

637

638

639

640

641 
643

644

645

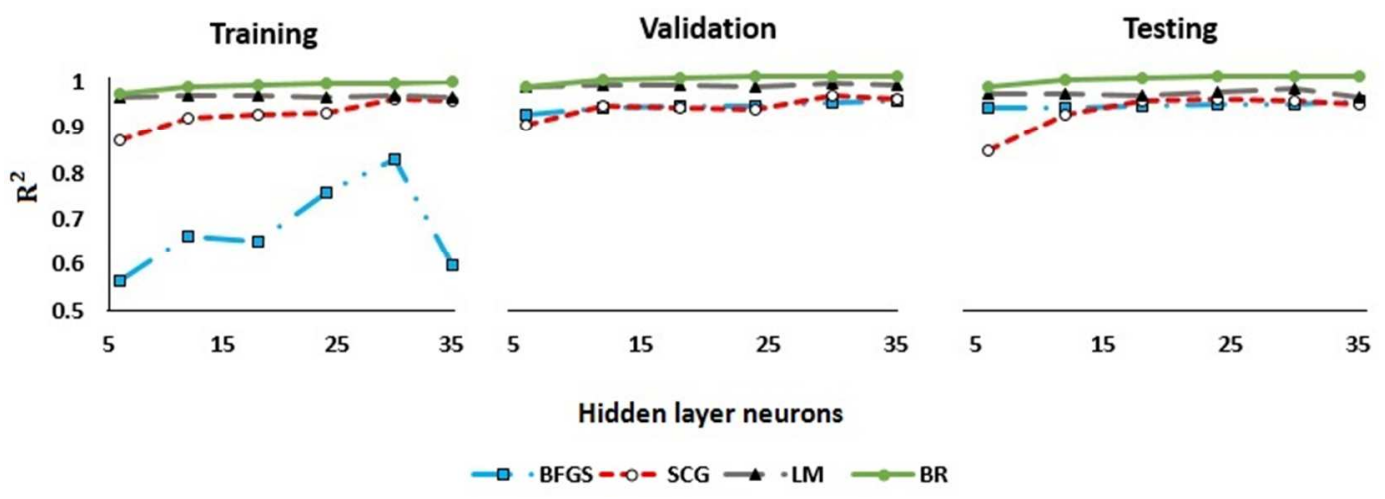

647

648

Figure 6.

649

650

651

652

653

654

655

656

657

658

659

660

661

662

663

664 
665

666

667

668

669

670

Figure 7.

671

672

673

674

675

676

677

678

679

680

681

682

683

684

https://mc06.manuscriptcentral.com/cjce-pubs 
IM1

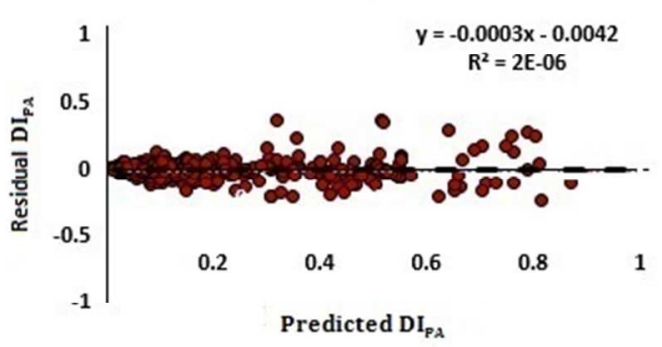

IM6

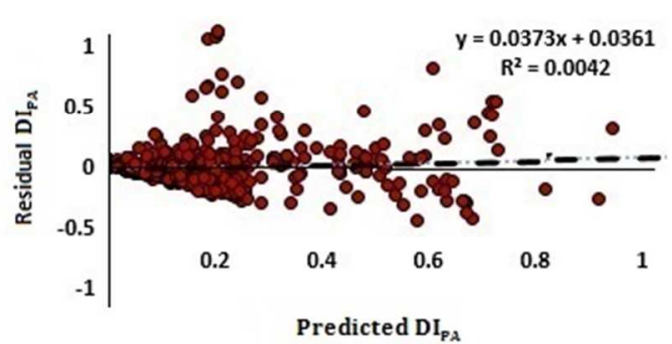

IM4
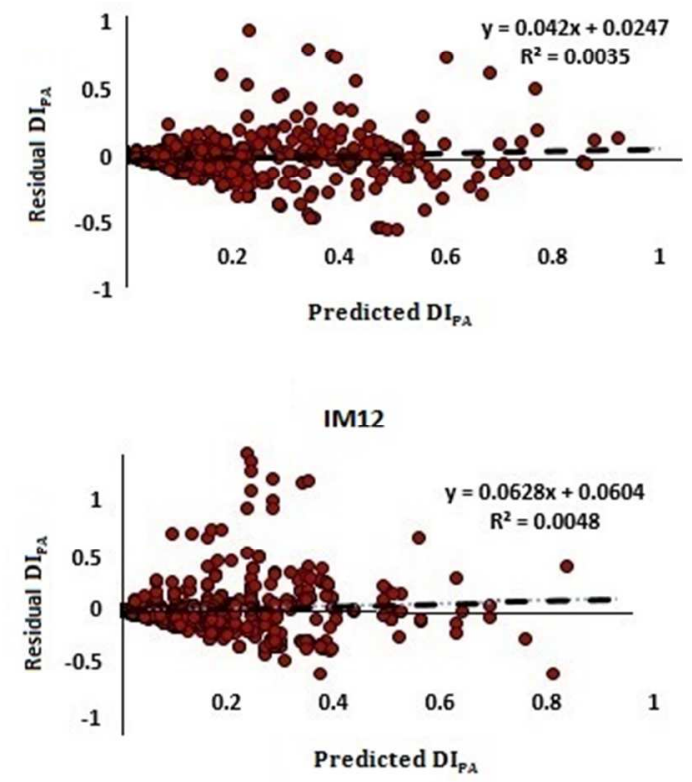
704

705

706

707

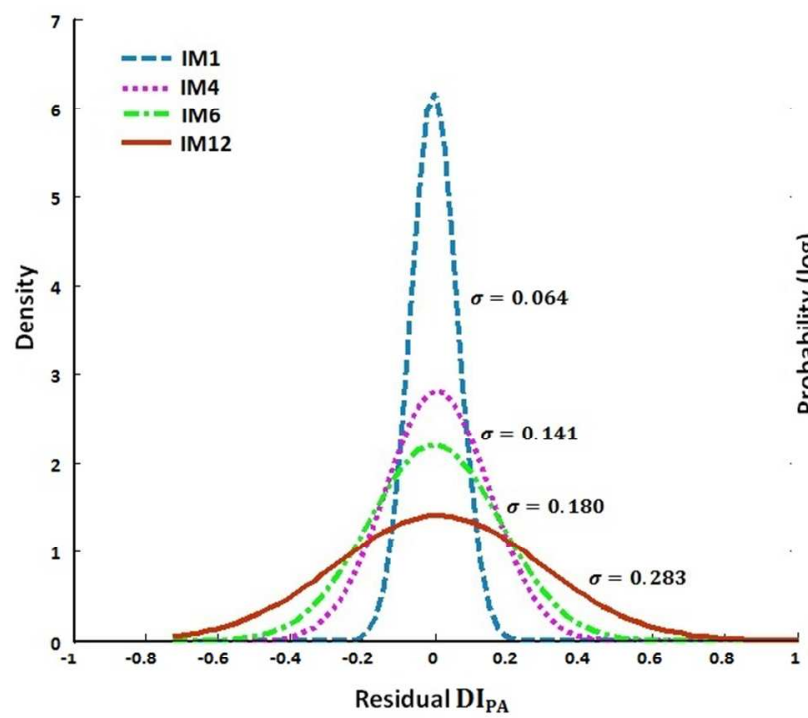

(a)

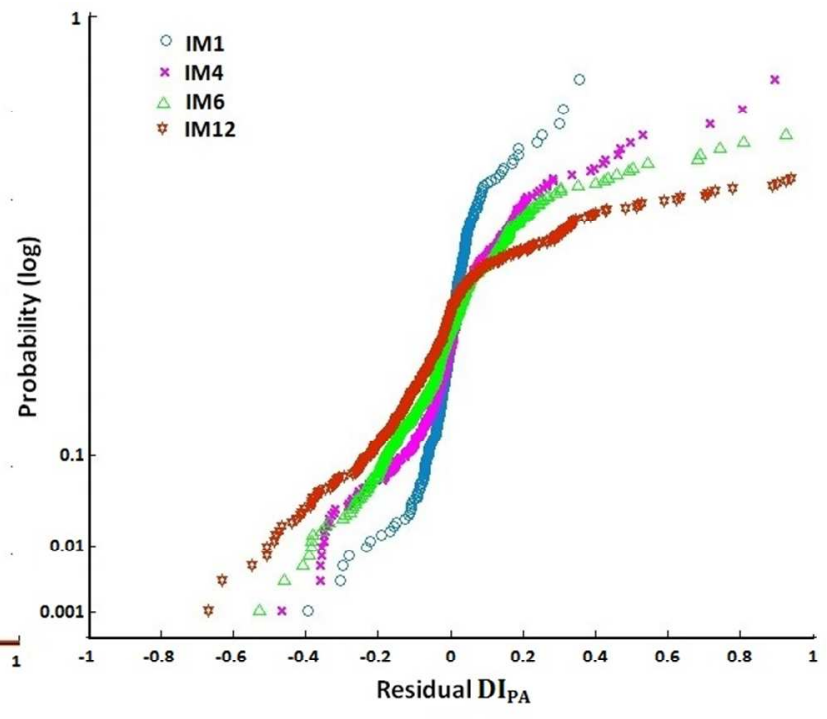

(b)

Figure 9.

710

711

712

713

714

715

716

717

718

719

720

721 

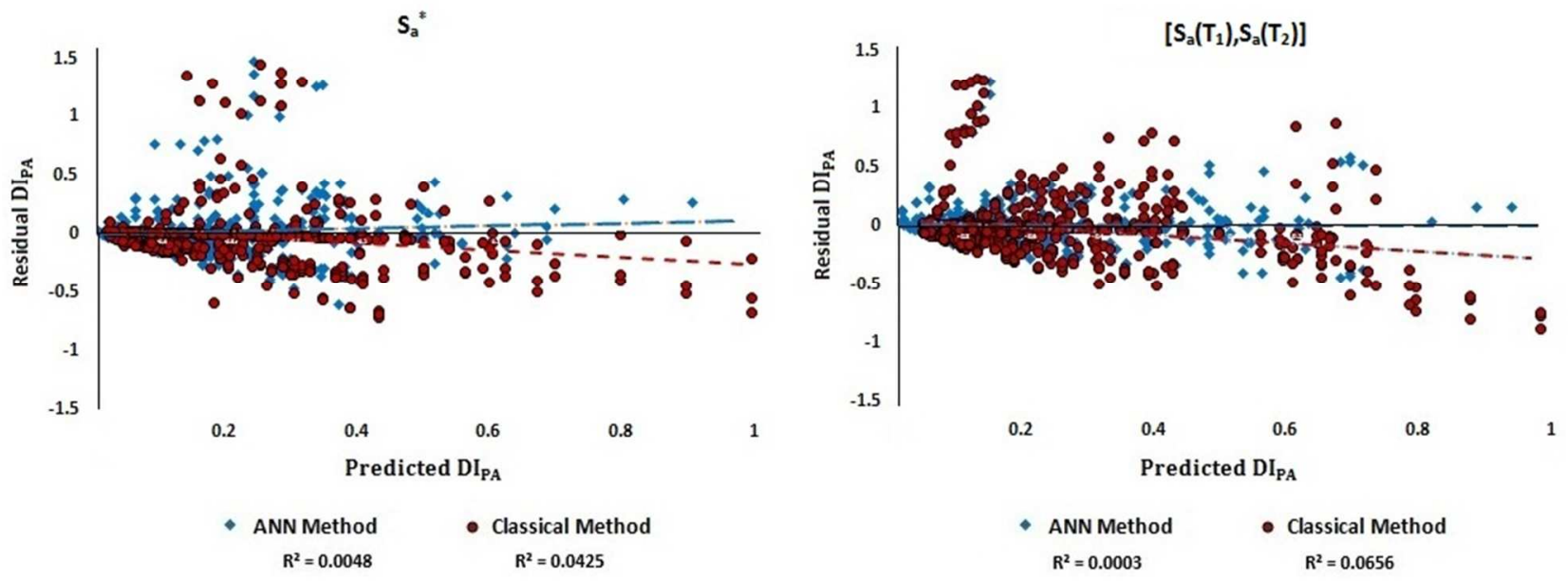

Figure 10.

729

730

731

732

733

734

735

736

737

738

739

740

741

742 

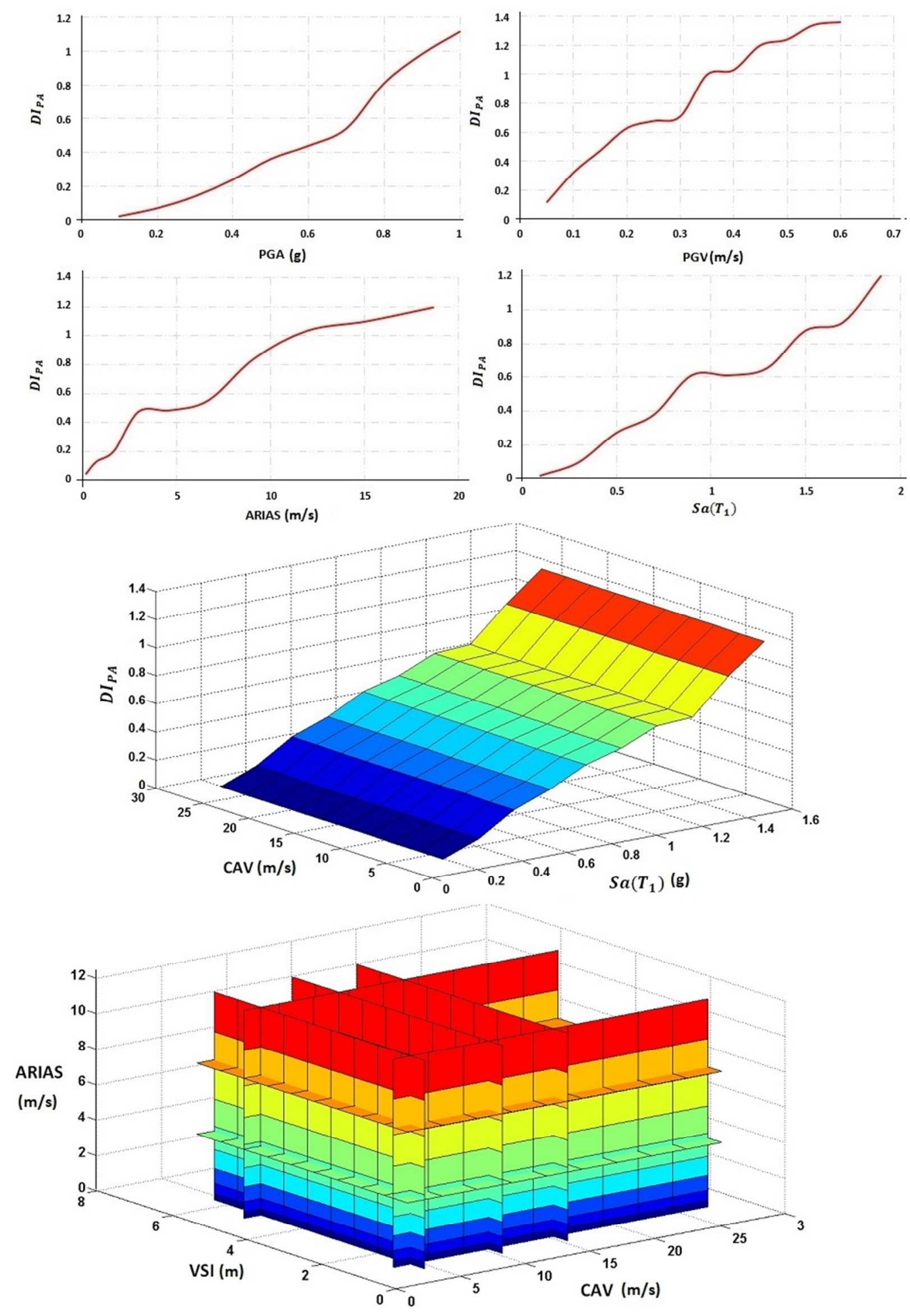


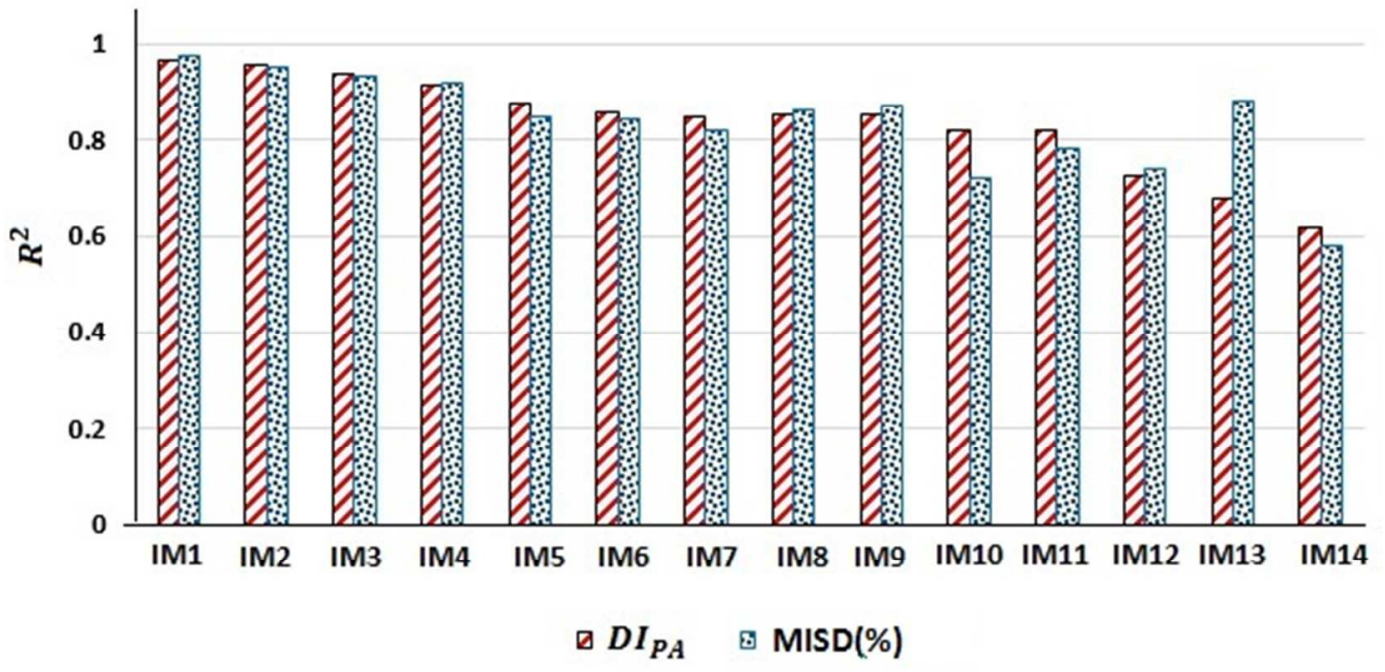

Figure 12.

753

754

755

756

757

758

759

760

761

762

763

764

765

766 

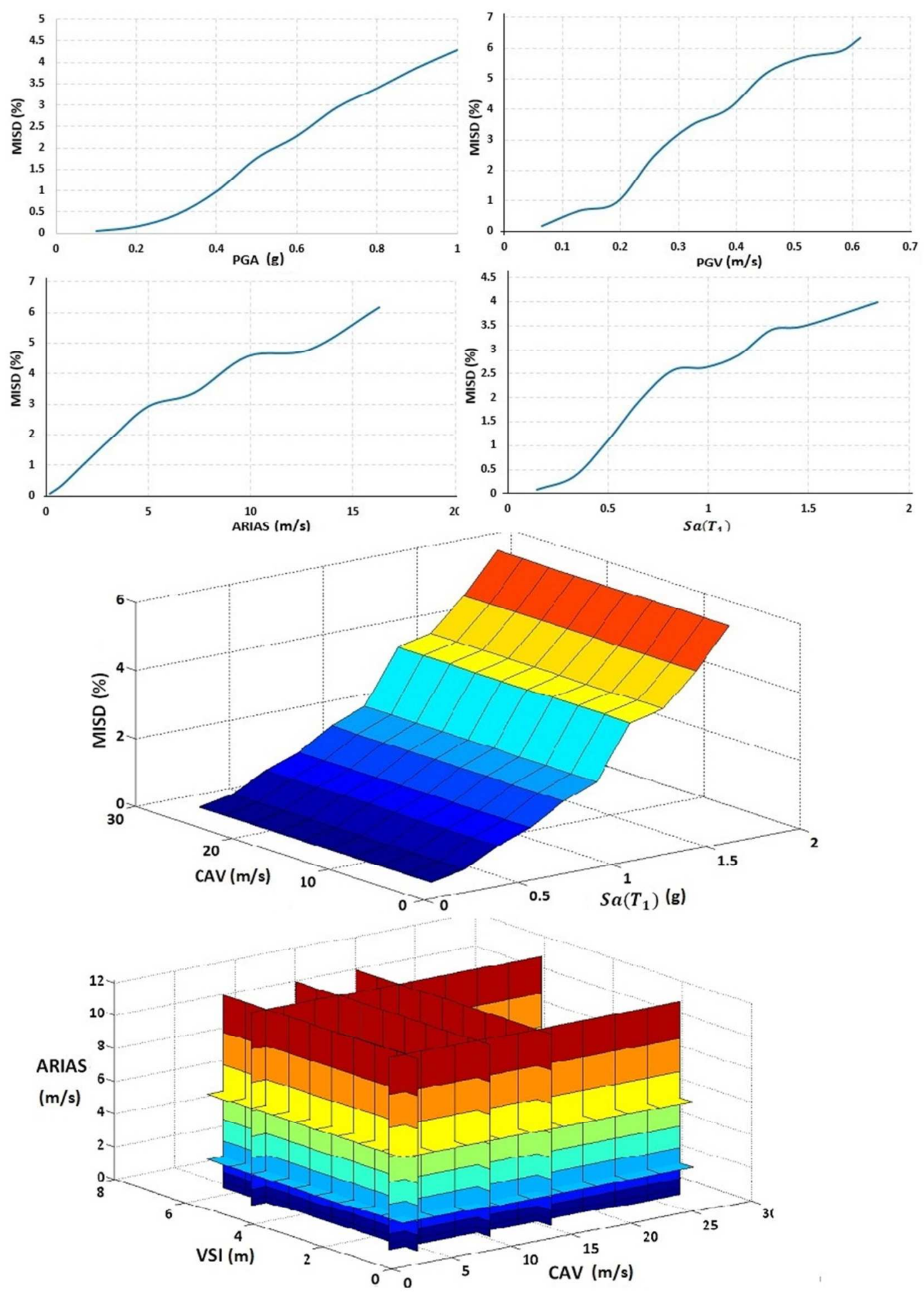

Figure 13. 